\title{
Polyethylene flame retarded with expandable graphite and a novel intumescent additive
}

Walter Wilhelm Focke ${ }^{1,{ }^{*}}$, Hermanus Joachim Kruger $^{1}$, Washington Mhike ${ }^{1}$, Albertus Taute ${ }^{1}$, Albert Roberson ${ }^{1}$ and Osei Ofosu ${ }^{2}$

${ }^{1}$ SARChI Chair in Carbon Technology and Materials, Institute of Applied Materials, Department of Chemical

Engineering, University of Pretoria, Private Bag X20, Hatfield 0028, South Africa

${ }^{2}$ CSIR Materials Science and Manufacturing, PO Box 1124, Port Elizabeth 6000, South Africa

Correspondence to: Walter W Focke (E-mail: walter.focke@up.ac.za)

\section{ABSTRACT}

A novel intumescent additive was synthesized by neutralizing 3,5-diaminobenzoic acid hydrochloride salt with ammonium dihydrogen phosphate. This compound, which melts at $257^{\circ} \mathrm{C}$, decomposes concurrently to release carbon dioxide gas. The flame retardant performance of this compound as a primary fire retardant and in combination with expandable graphite was evaluated by cone calorimetry. Cone calorimeter results revealed that addition of $10 \mathrm{wt}$.\% expandable graphite alone lowers peak heat release rate of carbon black-pigmented polyethylene from $710 \pm 109 \mathrm{~kW} \mathrm{~m}^{-2}$ to $342 \pm 15 \mathrm{~kW} \mathrm{~m}^{-2}$, while addition of $27 \mathrm{wt} . \%$ of the novel intumescent lowered it to $400 \pm 16 \mathrm{~kW} \mathrm{~m}^{-2}$. Combinations of these two additives were able to decrease the peak heat release rate even further. Furthermore, the novel intumescent additive reduced the flame out time from $773 \pm 307 \mathrm{~s}$ to $537 \pm 69 \mathrm{~s}$ although all other expandable graphite containing samples increased it.

\section{INTRODUCTION}

Polyethylenes are a family of commodity polymers (HDPE, LDPE, and LLDPE) primarily used as packaging materials. They are also used to fabricate moulded products such as battery boxes, air conditioning ducting, pipes and cable sheathing. Polyethylenes feature high heats of combustion and have a low propensity for char formation. ${ }^{1}$ As a result, these products present a potential fire hazard in certain applications, e.g. deep-level underground mining. Cone calorimetry presents a modern method for measuring the ignition time, heat release rate, combustion products and other flammability characteristics of polymer samples. This fire testing instrument determines the transient heat release rate by measuring transient oxygen consumption rate in the exhaust gases. According to Babrauskas ${ }^{2}$ the heat release rate is the most important single variable in characterizing the "flammability" of products and thus the fire hazard they may pose. Among the more widely used polymers, pure polyethylenes feature the highest heat release capacities and the highest heat release rates in cone calorimeter tests ${ }^{3}$.

It is therefore necessary, for critical applications, to flame retard polyethylene products with flame retardant additives. A wide range of effective additives are available. ${ }^{1,3}$ Recent studies have highlighted the utility of expandable graphite, intumescent flame retardants and their synergistic combinations 
which improve the fire behaviour of polyethylene. ${ }^{1,4-9}$ Intumescent additives cause the materials to swell when exposed to fire or heat to form a carbonaceous foam residue that acts as a heat insulator and a physical barrier to the transport of oxygen and pyrolysis products. ${ }^{3,10-12}$

Expandable graphite $(E G)$ is actually a partially oxidized, intercalated form of graphite containing intercalated guest species (e.g. sulfuric acid anions) in between the stacked graphene layers. ${ }^{13,14} \mathrm{~A}$ key property of expandable graphite is its tendency to exfoliate explosively, i.e. expand rapidly in a wormlike manner when heated to high temperatures. ${ }^{15-17}$ When this occurs at the surface of a polymer, the low density vermicular graphite that is formed provides a protective barrier similar to that generated by conventional intumescent additives.

According to Han and $\mathrm{Zhao}^{9}$ and Xie and $\mathrm{Qu}^{5}$ better fire properties are possible with combinations of EG and other intumescent flame retardants. Despite this, only a few such combinations have been explored to date. Therefore this communication reports on the synthesis and characterization of a novel intumescent flame retardant additive for use as a primary intumescent flame retardant and in combination with an expandable graphite. The unique aspect of these two additives is that they both feature relatively high thermal stabilities. This could make them useful in applications where the polymer conversion requires high processing temperatures, e.g. rotomoulding. The fire performance of these additives, on their own and in combinations, in polyethylene was studied using cone calorimeter fire testing.

\section{EXPERIMENTAL}

\section{Materials}

The chemicals 3,5-diamino benzoic acid [535-87-5], ammonium dihydrogen phosphate [7722-76-1] and hydrochloric acid [7647-01-0] were sourced from Sigma-Aldrich, Protea Chemicals and Merck respectively. Sasol Polymers supplied the low density polyethylene in powder and pellet form. It was injection moulding grade LT019 with density $0.919 \mathrm{~g} \mathrm{~cm}^{-3}$ and MFI 20.5g/10min @ 190 $\mathrm{C} / 2.16 \mathrm{~kg}$. Carbon black grade $\mathrm{N} 660$ was sourced from Ferro Industrial Products. The expandable graphite grade ES170 $300 \mathrm{~A}$, with a high expansion onset temperature, was sourced from Qingdao Kropfmuehl, China. The $\mathrm{d}_{10}$, $d_{50}$, and $d_{90}$ particle sizes are $313 \mu \mathrm{m}, 533 \mu \mathrm{m}$ and $807 \mu \mathrm{m}$ respectively (Mastersizer Hydroliser 2000, Malvern Instruments, Malvern, UK). The density was $2.23 \pm 0.01 \mathrm{~g} \mathrm{~cm}^{-3}$ and the surface area in the preexpanded form was $0.66 \mathrm{~m}^{2} \mathrm{~g}^{-1}$ (Nova 1000e BET in $\mathrm{N}_{2}$ at $77 \mathrm{~K}$ ).

\section{Synthesis of DABAP}

Scheme I shows the reaction details. The synthesis procedure was as follows: seven moles of 3,5diamino benzoic acid (1065 g) (DABA) was weighed out into a large glass container placed in an ice bath which contained ca. $500 \mathrm{~g}$ crushed ice. Seven ampules of concentrated hydrochloric acid (containing 1 mol HCl each) were added drop wise to the DABA container which was continuously stirred and maintained at a temperature below ambient. At this stage the solution developed a dark brown colour, most likely due to oxidation of a minor portion of the DABA. Next, seven moles (805 g) ammonium dihydrogen phosphate powder was added slowly to the reaction mixture with continued stirring. During 
this procedure the colour of the liquid phase changed from brown to orange. The final $\mathrm{pH}$ was 7.8 . The precipitated silver-white crystals were recovered using vacuum filtration. The filter cake was first washed with distilled water and then with acetone. The resulting filter cake was oven dried at $50{ }^{\circ} \mathrm{C}$ for $12 \mathrm{~h}$ and milled into a fine powder. The yield was $95 \%$.

\section{Preparation of the polyethylene compounds}

Polyethylene compounds containing expandable graphite and/or DABAP were compounded on a $28 \mathrm{~mm}$ co-rotating intermeshing twin screw laboratory extruder $(L / D=16)$ at a screw speed of $140-220 \mathrm{rpm}$. The compounder's screw design comprised intermeshing kneader elements with a forward transport action. The four extrusion processing stage temperatures, feed to die, were set at $120^{\circ} \mathrm{C}, 175{ }^{\circ} \mathrm{C}, 175^{\circ} \mathrm{C}$ and $180^{\circ} \mathrm{C}$ respectively. The extruded strands were granulated and pressed into flat sheets in a hot press set at $180^{\circ} \mathrm{C}$. The final sheet dimensions were $100 \mathrm{~mm} \times 100 \mathrm{~mm} \times 3.2 \pm 0.1 \mathrm{~mm}$. A polyethylene compound containing $3 \mathrm{wt}$.\% carbon black (N660) was prepared in a similar way. This compound was used as the reference sample for cone calorimeter testing. The compound containing $27 \mathrm{wt}$.\% DABAP also contained $3 \mathrm{wt}$.\% carbon black. This maintained a consistent range of dark product sheets as delivered for all expandable graphite containing compounds, in order to ensure comparable heat absorption during cone calorimeter testing.

\section{Characterization and analysis}

Fourier-Transform Infrared Spectroscopy (FTIR) spectra were recorded on a Perkin Elmer Spectrum RX FT-IR, coupled with a computer using Spectrum v5.0.1 software, with a scan resolution of $2.0 \mathrm{~cm}^{-1}$. A total of 32 interferograms were collected for each sample applying single beam radiation in an ATR configuration.

The compositions of the graphite particles and the DABAP were determined by X-ray fluorescence (XRF) analysis performed using a wavelength-dispersive spectrometer (ARL 9400XP+XRF). The samples were prepared as pressed powder briquettes and introduced to the spectrometer. The powders were ground in a tungsten carbide milling vessel and roasted at $1000^{\circ} \mathrm{C}$ for determination of the loss on ignition (LOI). SEM images were obtained using an ultrahigh resolution field emission SEM (HR FEGSEM Zeiss Ultra Plus 55 ) with an InLens detector at acceleration voltages of as low as $1 \mathrm{kV}$ to ensure maximum resolution of surface detail. No electro-conductive coating was applied on the graphite particles.

\section{Thermal analysis}

Differential scanning calorimetry data were obtained on a Perkin Elmer PYRIS Diamond DSC. The temperature was scanned from $30^{\circ} \mathrm{C}$ to $370{ }^{\circ} \mathrm{C}$ at a scan rate of $10^{\circ} \mathrm{C} \mathrm{min}$ with nitrogen flowing at a

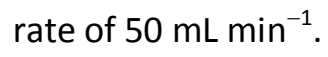

Thermogravimetric analysis (TGA) was performed using the dynamic method on a TA Instruments SDT Q600 instrument. About $7 \mathrm{mg}$ of sample was placed in a $50 \mu \mathrm{L}$ alumina pan with an alumina lid.

Temperature was scanned from $50{ }^{\circ} \mathrm{C}$ to $900^{\circ} \mathrm{C}$ at a scan rate of $10^{\circ} \mathrm{C} \mathrm{min}^{-1}$ with gas flowing at a rate of $50 \mathrm{~mL} \mathrm{~min}^{-1}$. 
Thermal expansion measurements were conducted on a TA instruments Q400 Thermo Mechanical Analyzer. Sufficient expandable graphite powder was placed in an alumina sample pan such that the bed height was between $35 \mu \mathrm{m}$ and $40 \mu \mathrm{m}$. The flake expansion behaviour was measured with a flat-tipped standard expansion probe using an applied force of $0.02 \mathrm{~N}$. The temperature was scanned from $30^{\circ} \mathrm{C}$ to $1000^{\circ} \mathrm{C}$ at a scan rate of $10^{\circ} \mathrm{C} \mathrm{min}^{-1}$ in a nitrogen atmosphere. The expansion relative to the original powder bed height was reported. The same procedure was used to determine the softening point of the DABAP using a thin tipped penetration probe. In this case however, the applied force was $0.01 \mathrm{~N}$, the temperature was scanned from $30{ }^{\circ} \mathrm{C}$ to $500{ }^{\circ} \mathrm{C}$ at a scan rate of $4{ }^{\circ} \mathrm{C} \mathrm{min}-1$ and the starting sample height was $229 \mu \mathrm{m}$.

\section{Cone calorimeter flammability testing}

The ISO 5660-1 standard was followed in performing the cone calorimeter tests using a Dual Cone Calorimeter (Fire Testing Technology (UK) Ltd.). Three specimens of each composition were tested and average values are reported. The sheet dimensions were $100 \mathrm{~mm} \times 100 \mathrm{~mm} \times 3.2 \mathrm{~mm}$. They were placed horizontally on aluminium foil and exposed perpendicularly from above to an external heat flux of $35 \mathrm{~kW} \mathrm{~m}^{-2}$.

\section{RESULTS AND DISCUSSION}

\section{Characterization}

The synthesis yielded the phosphate salt of 3,5-diamino benzoic acid (DABAP) as shown by the reactions of Scheme I. It is expected that one of the amine functional groups of 3,5-diamino benzoic acid became protonated by the phosphoric acid while the other remained a free amine (that nevertheless participates in hydrogen bonding). The FTIR spectrum shown in Fig. 1 is consistent with these assertions. The presence of a free primary aromatic amine is supported by the following absorption peaks in the FTIR spectrum: ${ }^{18}$ The two bands located at $3469 \mathrm{~cm}^{-1}$ and $3377 \mathrm{~cm}^{-1}$ are characteristic of the $\mathrm{N}-\mathrm{H}$ stretching vibrations in primary amines. The sharp band at 1600 is due to the $\mathrm{N}-\mathrm{H}$ bending vibration in primary amines. The band at $1340 \mathrm{~cm}^{-1}$ is characteristic of the $\mathrm{C}-\mathrm{N}$ stretch of aromatic amines. Finally, the sharp peak at $763 \mathrm{~cm}^{-1}$ is consistent with the $\mathrm{N}-\mathrm{H}$ wagging vibration of primary amines. The band at $1050 \mathrm{~cm}^{-1}$ is attributed to the phosphate ion. The broad band with a peak at $2917 \mathrm{~cm}^{-1}$ is consistent with the presence of a primary ammonium ion ( $\mathrm{N}-\mathrm{H}$ stretch). The primary ammonium ion $\mathrm{N}-\mathrm{H}$ bending vibrations are indicated by the two bands located at $1530 \mathrm{~cm}^{-1}$ and $1475 \mathrm{~cm}^{-1}$. 


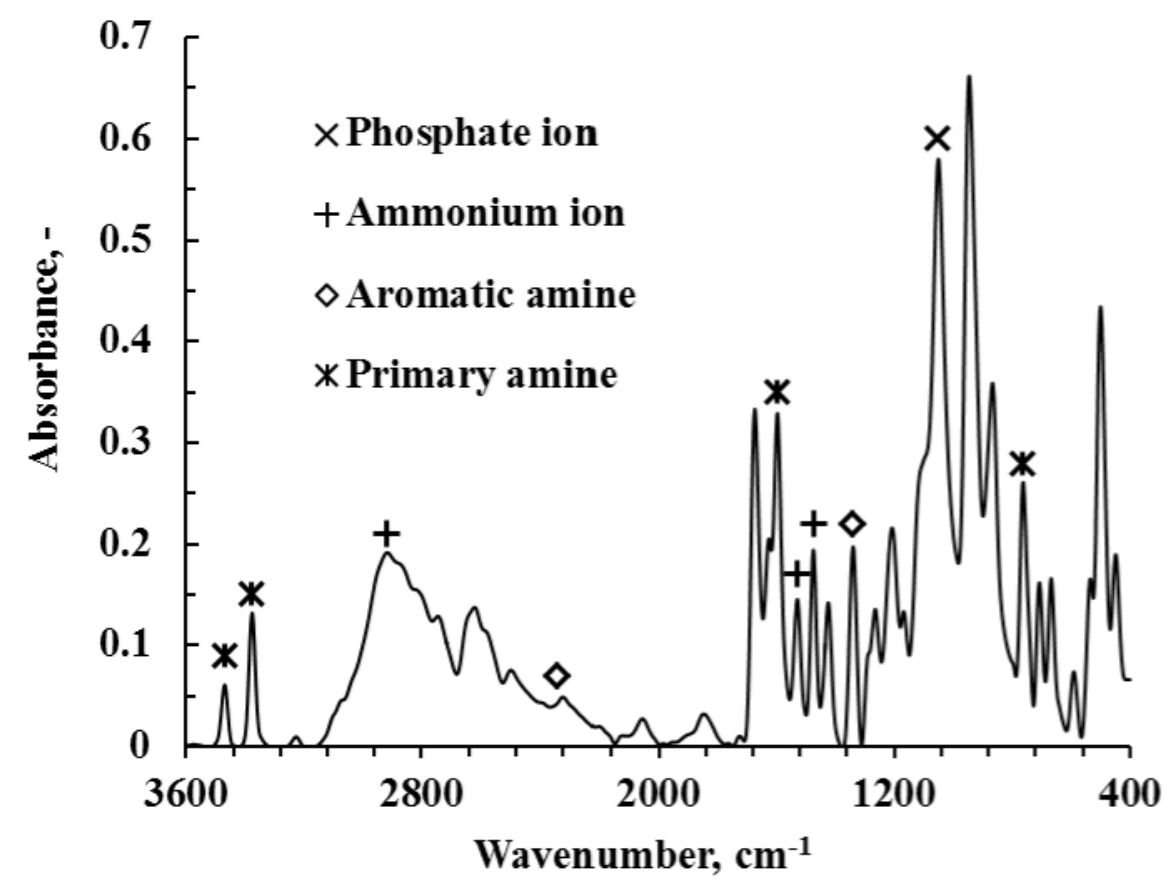

FIGURE 1 FTIR spectrum for 3,5-diaminobenzoic acid phosphate (DABAP)<smiles>Nc1cc(N)cc(C(=O)O)c1</smiles><smiles>Nc1cc([NH2+][NH2+]c2cc(N)cc(C(=O)O)c2)cc(C(=O)O)c1</smiles>

Scheme I. Synthesis of the phosphate salt of 3,5-diaminobenzoic acid 
TABLE 1 XRF results with composition indicated as wt.\%

\begin{tabular}{cccccccc}
\hline & $\mathrm{SiO}_{2}$ & $\mathrm{TiO}_{2}$ & $\mathrm{Al}_{2} \mathrm{O}_{3}$ & $\mathrm{Fe}_{2} \mathrm{O}_{3}$ & $\mathrm{MnO}$ & $\mathrm{MgO}$ & $\mathrm{CaO}$ \\
& 1.06 & 0.02 & 0.63 & 0.10 & 0.03 & 0.16 & 1.58 \\
\cline { 2 - 8 } ES170 300A & $\mathrm{Na}_{2} \mathrm{O}$ & $\mathrm{K}_{2} \mathrm{O}$ & $\mathrm{SO}_{3}$ & $\mathrm{Co}_{3} \mathrm{O}_{4}$ & $\mathbf{S}$ & Rest & \\
& 0.48 & 0.07 & 6.06 & $<0.01$ & $<0.01$ & 89.67 & \\
\hline \multirow{2}{*}{ DABAP } & $\mathrm{Fe}_{2} \mathrm{O}_{3}$ & $\mathbf{M g O}$ & $\mathrm{Na}_{2} \mathbf{O}$ & $\mathrm{P}_{2} \mathrm{O}_{5}$ & $\mathrm{SO}_{3}$ & $\mathbf{C l}$ & Rest \\
& 0.05 & 0.04 & 0.29 & 25.47 & 0.02 & 0.68 & 73.46 \\
\hline
\end{tabular}

Table 1 reports the XRF results for DABAP and the expandable graphite. According to the XRF results, the apparent $\mathrm{P}_{2} \mathrm{O}_{5}$ content of DABAP is $25.47 \%$ whereas the expected, i.e. theoretical value is $28.37 \%$. The chlorine content suggests co-crystallization of the chloride salt of 3,5-diamino benzoic acid. Both samples contain some inorganic impurities. In DABAP the source is probably the technical grade ammonium dihydrogen phosphate that was used. The expandable graphite contains intercalated sulphuric acid moieties and as expected the XRF results revealed the presence of a significant amount of sulphur. However, the graphite sample also contains other inorganic impurities. The main impurity elements were silicon and aluminium suggesting that the precursor graphite may have been contaminated with clay minerals.

The SEM micrograph in Figure 2 shows the morphology of the DABAP crystals. The expandable graphite particles also have a flake-like nature but the flakes are much larger.

\section{Thermal analysis}

Figure 3 shows the TGA mass loss curve and the DTG curves for DABAP obtained in $\mathrm{N}_{2}$, together with the TGA trace for the expandable graphite obtained in nitrogen and air. The mass loss for the EG in air occurs in two steps. The first corresponds to the gas released during the exfoliation event and this one is also observed in a nitrogen atmosphere. The mass loss in air and nitrogen at $600{ }^{\circ} \mathrm{C}$ amount to $10 \mathrm{wt} . \%$ and $7 \mathrm{wt} . \%$ respectively. The second corresponds to the oxidation of graphite residue. The mass loss for the DAPAB occurs in four steps. The minor mass loss $(1.17 \%)$ below $200{ }^{\circ} \mathrm{C}$ probably reflects the loss of moisture. Thereafter a steep mass loss (ca. 15.5\%) event occurs with an onset temperature of $254{ }^{\circ} \mathrm{C}$. This probably reflects the loss of $\mathrm{CO}_{2}$ due to the decarboxylation of the DABAP. The theoretical mass loss for decarboxylation is $17.6 \%$. Mass loss continues and next reaches a peak value at a temperature of $446{ }^{\circ} \mathrm{C}$. We attribute this to the char-forming decomposition reaction that also releases ammonia gas. The pyrolysis of the char that is formed continues as the temperature is raised. It reaches a maximum 

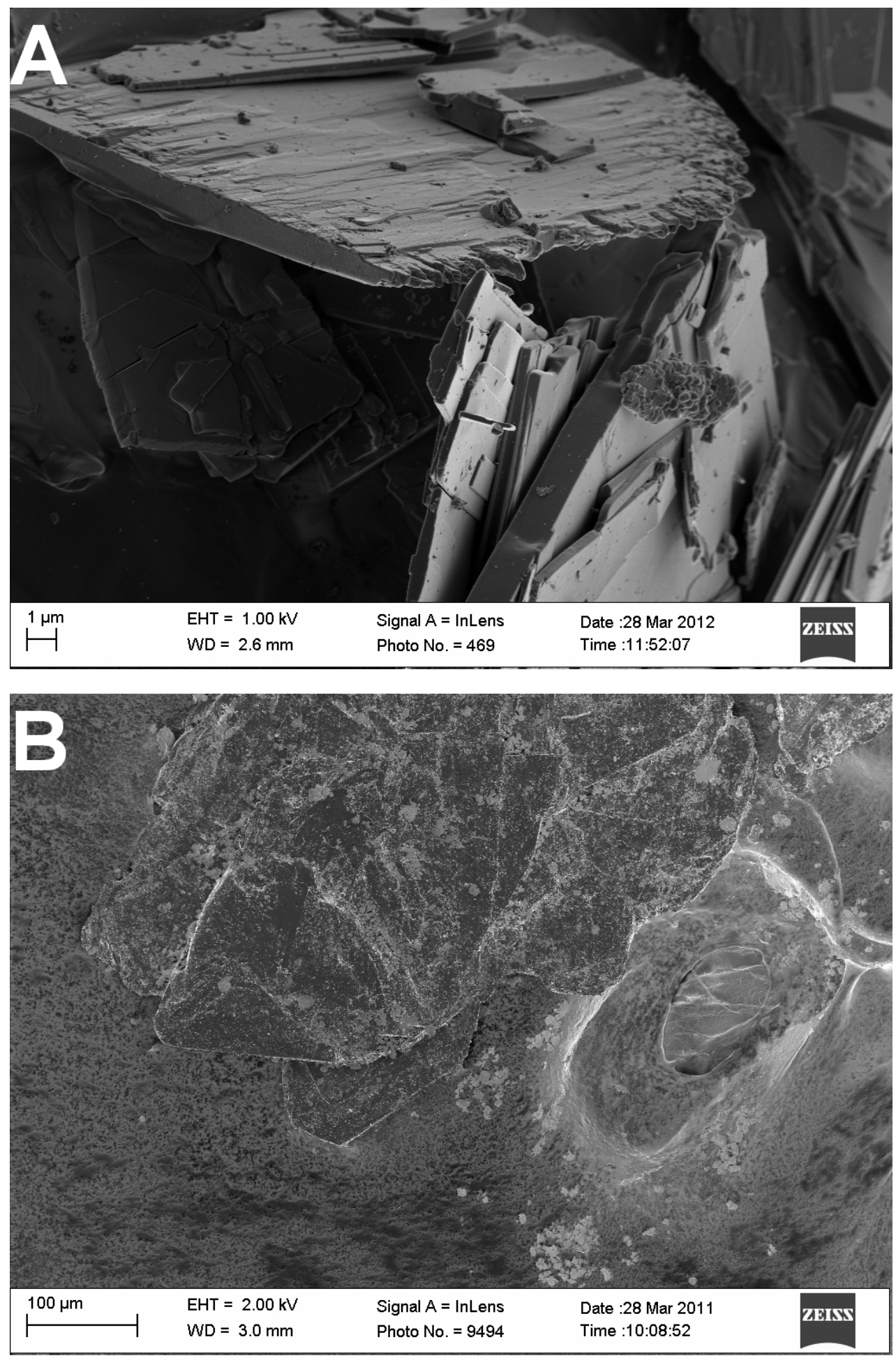

FIGURE 2 SEM micrographs of (A) 3,5-diaminobenzoic acid phosphate crystals and (B) expandable graphite flakes. 
rate at $860^{\circ} \mathrm{C}$. At $900{ }^{\circ} \mathrm{C}$, the carbonized char residue that remains represents just above $27 \%$ of the initial DABAP mass.

Fig. 4 shows the DTA curves together with the TGA trace for DABAP. It is clear from this figure that all the mass loss events seen in the TGA are associated with endothermic events. The DSC scan in Fig. 5 indicates a sharp endothermic peak with an onset temperature of $257^{\circ} \mathrm{C}$. The shape and the corresponding enthalpy change of $624 \mathrm{~kJ} \mathrm{~kg}^{-1}$ are reminiscent of a melting event. Indeed, the TMA curve in Fig. 5 indicates softening of the material at this temperature. In conclusion, the melting of DABAP commences with simultaneously thermal decomposition at about $257^{\circ} \mathrm{C}$.

The key property of expandable graphite in fire retardant applications is the ability to exfoliate within a narrow temperature range. Fig. 6 compares the TMA expansion performance of the expandable

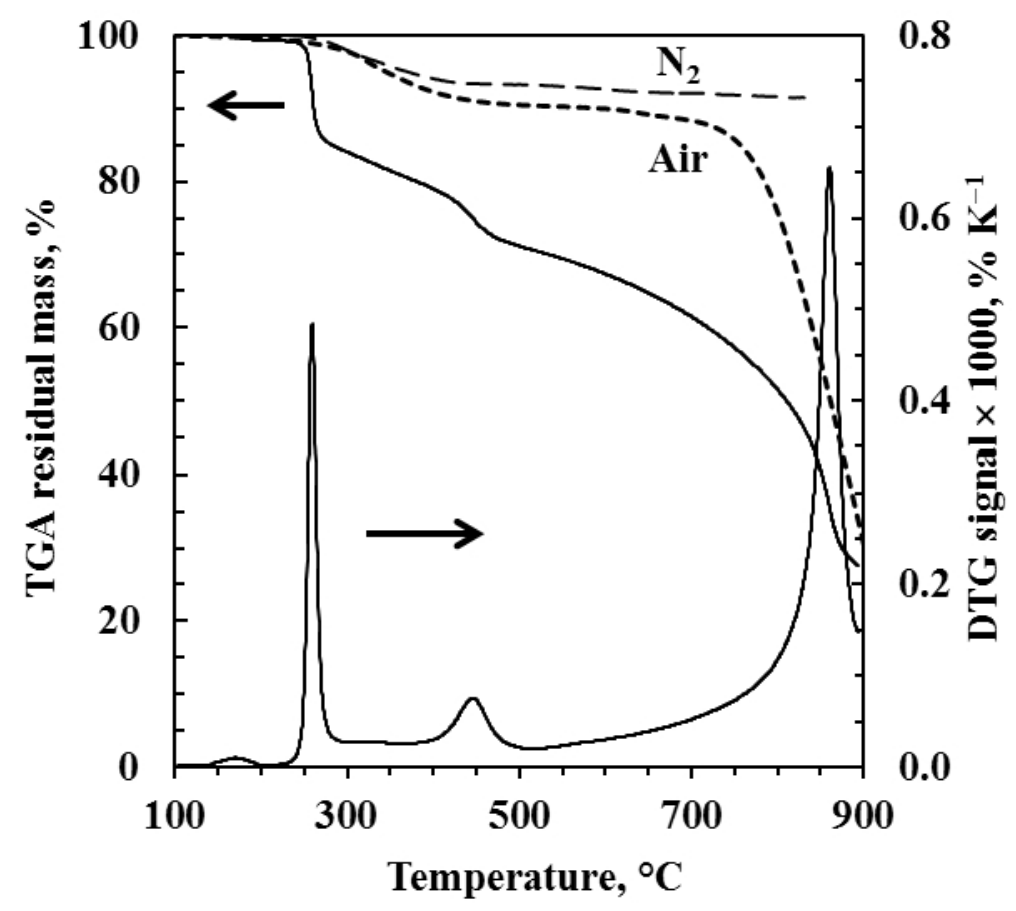

FIGURE 3 TGA and DTG curves for DABAP obtained in $\mathrm{N}_{2}$ and TGA traces for the expandable graphite in air and in nitrogen (dotted lines). Temperature was scanned from $25^{\circ} \mathrm{C}$ to $900{ }^{\circ} \mathrm{C}$ at a scan rate of $10{ }^{\circ} \mathrm{C} \mathrm{min}^{-1}$ with gas flowing at a rate of $50 \mathrm{~mL} \mathrm{~min}^{-1}$. 


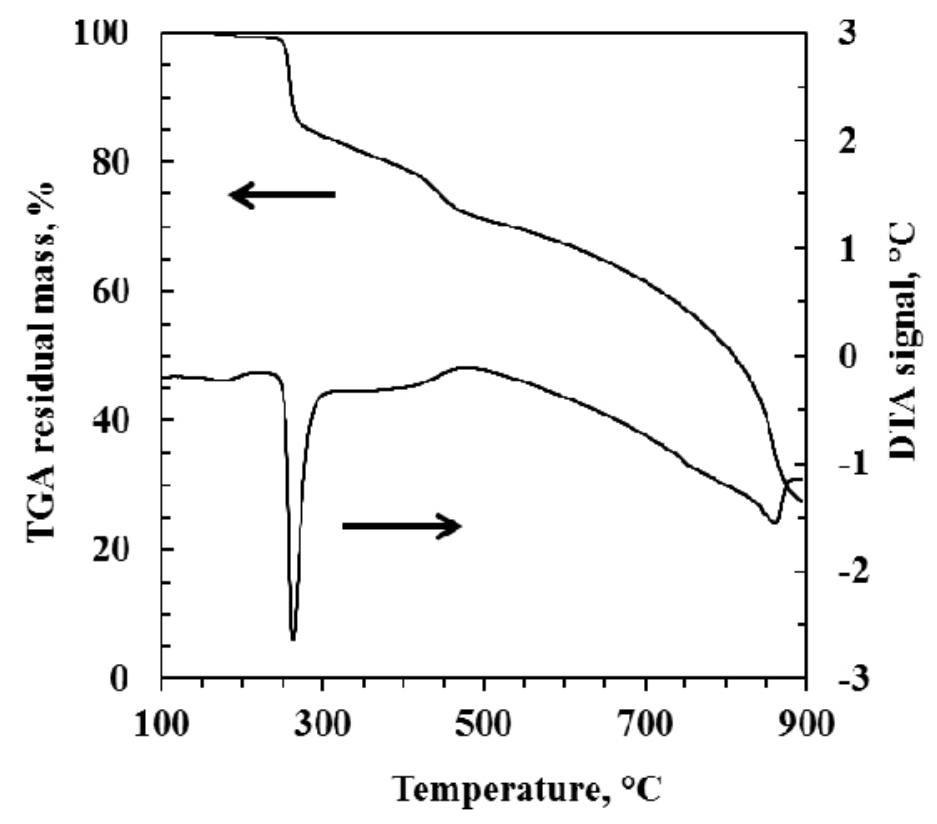

FIGURE 4 TGA and DTA curves for DABAP obtained at a scan rate of $10^{\circ} \mathrm{C} \mathrm{min}^{-1}$ with $\mathrm{N}_{2}$ gas flowing at a rate of 50 $\mathrm{mL} \mathrm{min}^{-1}$.

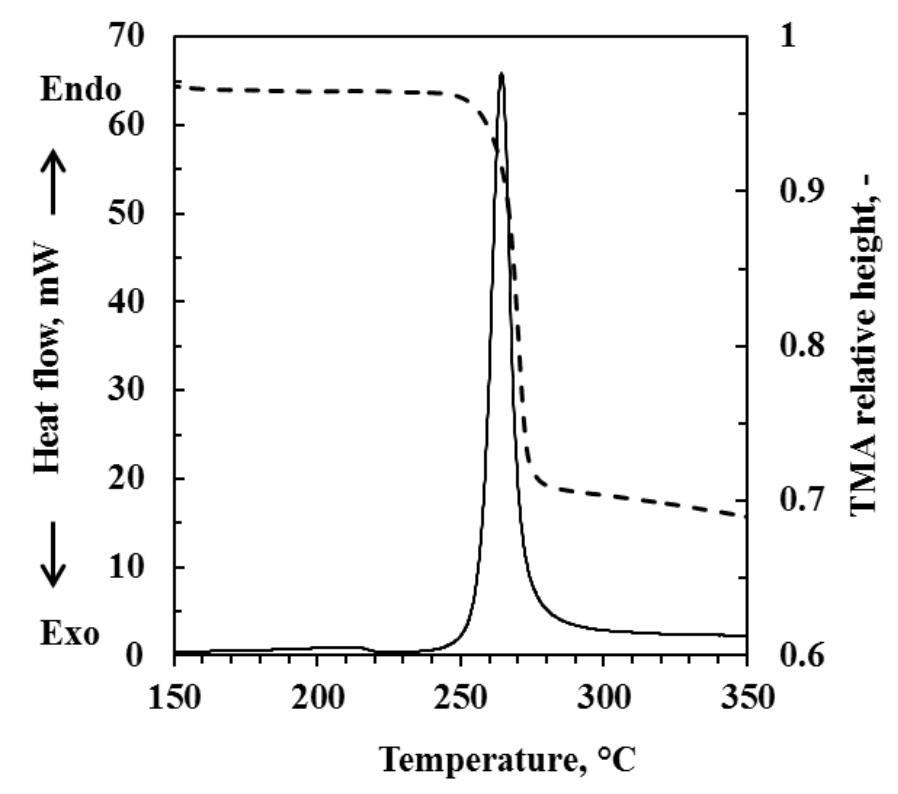

FIGURE 5 DSC and TMA curves for DABAP obtained with $\mathrm{N}_{2}$ gas flowing at a rate of $50 \mathrm{~mL} \mathrm{~min}^{-1}$. The temperature scan rates were $10^{\circ} \mathrm{C} \mathrm{min}^{-1}$ and $4{ }^{\circ} \mathrm{C} \mathrm{min}^{-1}$ respectively. 


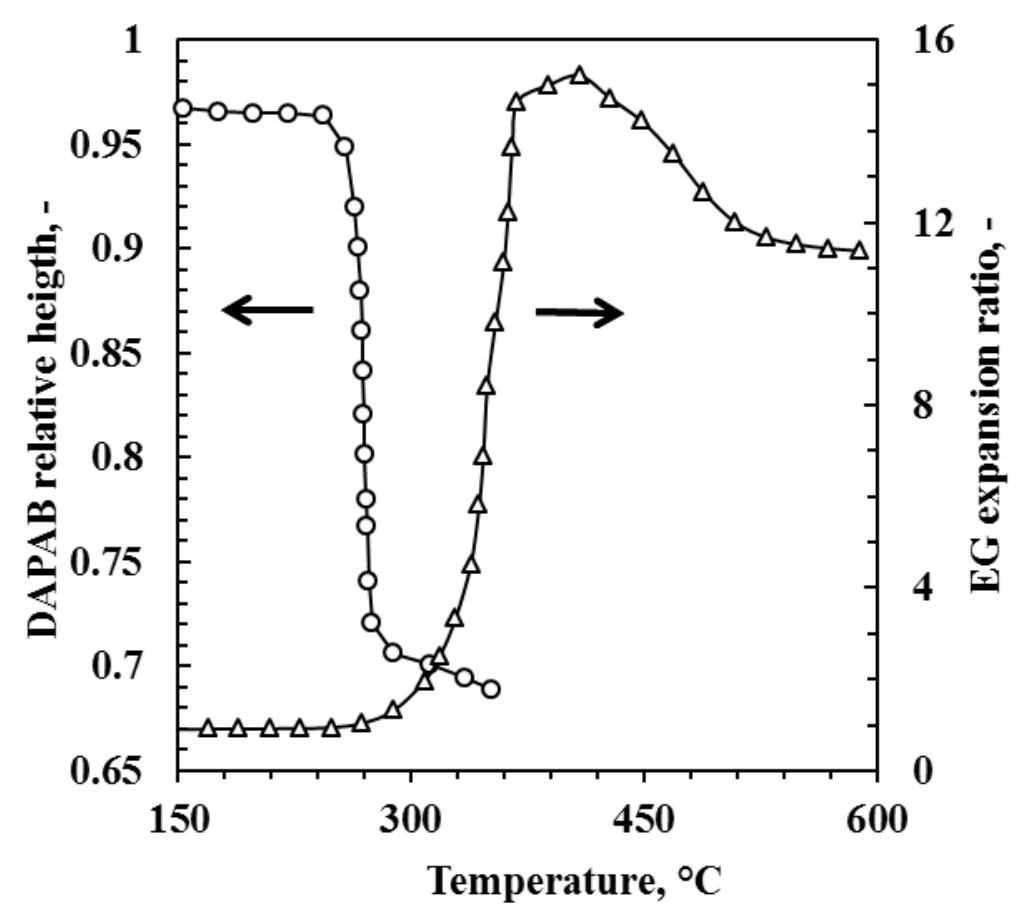

FIGURE 6 Thermomechanical characterization of the softening of DABAP and the exfoliation process of the expandable graphite (EG) in a nitrogen atmosphere. The temperature was scanned at rates of $4{ }^{\circ} \mathrm{C} \mathrm{min}{ }^{-1}$ and $10{ }^{\circ} \mathrm{C}$ $\mathrm{min}^{-1}$ respectively. A penetration probe was used for the DABAP and a flat-tipped standard expansion probes was used for the EG. The applied force was $0.01 \mathrm{~N}$ for the DABAP and $0.02 \mathrm{~N}$ for the expandable graphite.

graphite sample with the behaviour of DABAP. The exfoliation onset temperature of the EG was ca. 300 ${ }^{\circ} \mathrm{C}$. It is clear that the DABAP softened well before the onset of the EG expansion which promotes expansion of EG through DABAP thus increasing the thermal barrier thickness.

\section{Flammability}

The cone calorimeter results are presented in Figure 7 to Figure 13 and are summarized in Table 2. Figure 7 shows representative heat release rate $(H R R)$ curves obtained from the cone calorimeter tests. Figures 8 reports average values for the total heat released and the peak heat release rates. Unexpectedly the total heat release value measured was lowest for the carbon black-pigmented polyethylene, hereafter referred to as neat polyethylene (Table 2). It was $90 \pm 18 \mathrm{MJ} \mathrm{m}^{-2}$ for the neat polyethylene and $130 \pm 6 \mathrm{MJ} \mathrm{m}^{-2}$ for the compound with 27 wt.\% DABAP. Intermediate values were measured for the other compounds.

All the neat samples ignited and flamed for extended periods of time. The heat release curves for the neat polyethylene compound exhibited the shape characteristic of a thermally thin sample. ${ }^{19}$ Thermally thin samples are identified by a sharp peak in their HRR curves as the whole sample is pyrolyzed at once. $H R R$ curves characteristic of thermally thick, char-producing samples show a sudden rise to a plateau value. ${ }^{19}$ The HRR curves for the flame retarded samples approach this shape. They showed a rapid rise 
TABLE 2 Cone calorimeter data summary

\begin{tabular}{|c|c|c|c|c|c|c|}
\hline \multirow[b]{2}{*}{ Property } & \multirow[b]{2}{*}{ Units } & \multicolumn{2}{|c|}{ EG/DABAP, wt.\% } & \multirow[b]{2}{*}{$0 / 27$} & \multirow[b]{2}{*}{$10 / 10$} & \multirow[b]{2}{*}{$10 / 20$} \\
\hline & & $0 / 0$ & $10 / 0$ & & & \\
\hline Time to ignition $\left(t_{\text {ign }}\right)$ & $\mathrm{s}$ & $58 \pm 3$ & $46 \pm 1$ & $33 \pm 5$ & $39 \pm 3$ & $41 \pm 1$ \\
\hline Time to $p H R R$ & s & $177 \pm 6$ & $92 \pm 3$ & $105 \pm 13$ & $72 \pm 6$ & $75 \pm 0$ \\
\hline Time to flame out & $\mathrm{s}$ & $773 \pm 307$ & $869 \pm 68$ & $537 \pm 69$ & $993 \pm 46$ & $1124 \pm 106$ \\
\hline Total heat release $(t H R)$ & $\mathrm{MJ} \mathrm{m}^{-2}$ & $90 \pm 18$ & $130 \pm 5$ & $103 \pm 3$ & $109 \pm 7$ & $102 \pm 10$ \\
\hline Peak heat release rate $(p H R R)$ & $\mathrm{kW} \mathrm{m} \mathrm{m}^{-2}$ & $710 \pm 109$ & $342 \pm 15$ & $400 \pm 16$ & $282 \pm 3$ & $252 \pm 24$ \\
\hline MAHRE & $\mathrm{MJ} \mathrm{m}^{-2}$ & $316 \pm 47$ & $199 \pm 13$ & $276 \pm 12$ & $168 \pm 6$ & $146 \pm 7$ \\
\hline FIGRA & $k W m^{-2} s^{-1}$ & $4.01 \pm 0.52$ & $3.73 \pm 0.09$ & $3.86 \pm 0.68$ & $3.95 \pm 0.37$ & $3.36 \pm 0.32$ \\
\hline$p H R R / t_{\text {ign }}$ & $k W m^{-2} s^{-1}$ & $12.2 \pm 2.2$ & $7.38 \pm 0.41$ & $12.4 \pm 2.7$ & $7.31 \pm 0.55$ & $6.15 \pm 0.71$ \\
\hline
\end{tabular}




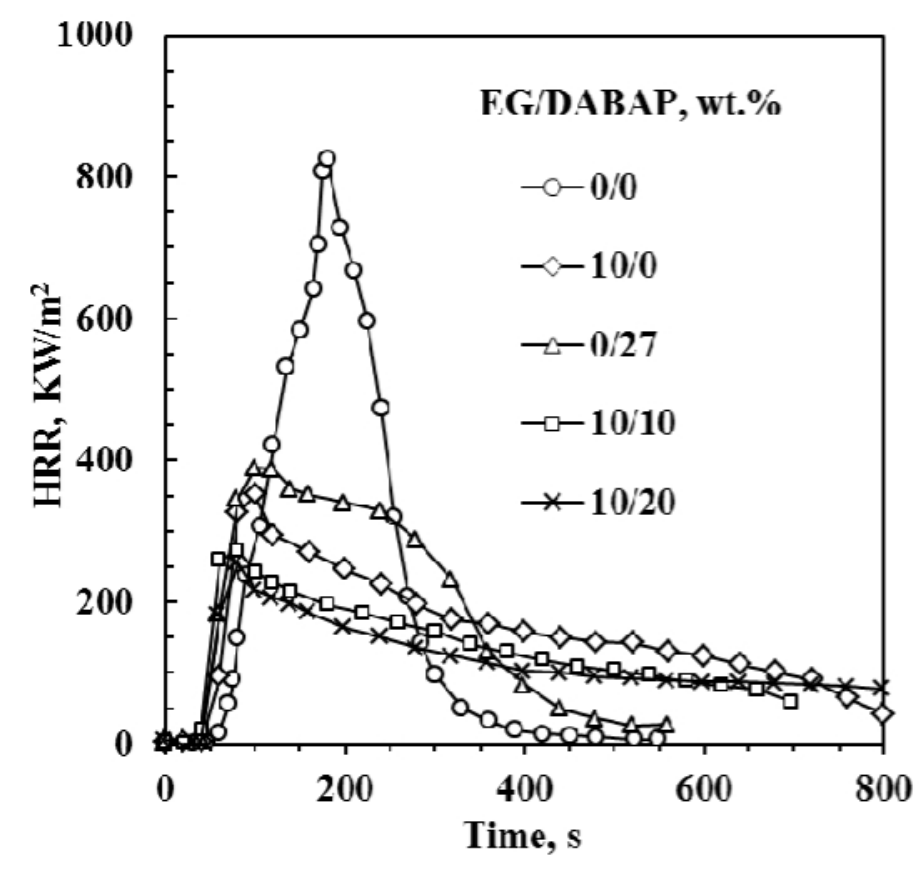

FIGURE 7 Cone calorimeter heat release rate curves for the polyethylene compounds with expandable graphite and DABAP. The sample sheets were backed by aluminium foil and their dimensions were $100 \mathrm{~mm} \times 100 \mathrm{~mm} \times 3.2$ $\mathrm{mm}$. They were mounted horizontally and exposed from above to an external heat flux of $35 \mathrm{~kW} \mathrm{~m}^{-2}$.

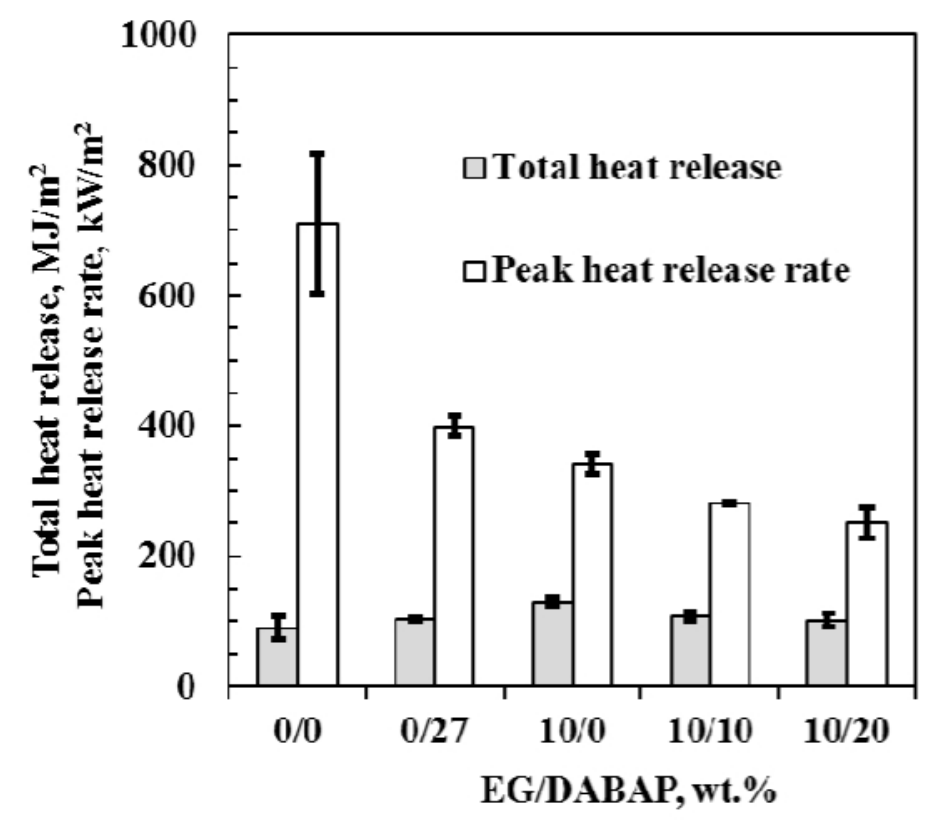

FIGURE 8 Cone calorimeter peak heat release rates and total heat release for the polyethylene compounds with expandable graphite and DABAP. The sample sheets were backed by aluminium foil and their dimensions were 100 $\mathrm{mm} \times 100 \mathrm{~mm} \times 3.2 \mathrm{~mm}$. They were mounted horizontally and exposed from above to an external heat flux of 35 $\mathrm{kW} \mathrm{m} \mathrm{m}^{-2}$. 
after ignition followed by a slower downward taper. The $H R R$ curve for the $27 \mathrm{wt} . \%$ DABAP compound showed a third phase where a faster decay in the heat release rate occurred. All the flame retarded samples expanded during the fire test but expansion was more pronounced in the samples containing EG. Figure 8 shows the effect of adding both EG and DABAP on the peak heat release rates $(p H R R)$ and the total heat release. The $p H R R$ results are also tabulated in Table 2 . The $p H R R$ for the neat polyethylene was $710 \pm 109 \mathrm{~kW} \mathrm{~m}^{-2}$. The best result was obtained from $10 \mathrm{wt} . \%$ EG plus $20 \mathrm{wt} . \%$ DABAP $\left(252 \pm 24 \mathrm{~kW} \mathrm{~m}^{-2}\right)$ but even addition of $10 \mathrm{wt} . \% \mathrm{EG}$ alone reduced the value to $342 \pm 15 \mathrm{~kW} \mathrm{~m}^{-2}$. Table 2 shows that the $10 \mathrm{wt} . \% \mathrm{EG}$ compound is more effective at reducing the $p H R R$ than the $27 \mathrm{wt} . \%$ DABAP compound. The improved fire performance with respect to the peak heat release rate is attributed to the formation of a heat-insulating protective barrier at the solid surface. This limited heat transfer to the substrate and thus slowed down the rate of thermal degradation.

Figure 9 confirms that the addition of the EG reduced the mass loss rate (MLR). This can be attributed to the expansion of the intercalated graphite which forms a low density layer of loose 'worm like' structures at the surface. Visual inspection of the residues showed that the DABAP containing compounds formed a denser charred foam layer at the polymer interface.

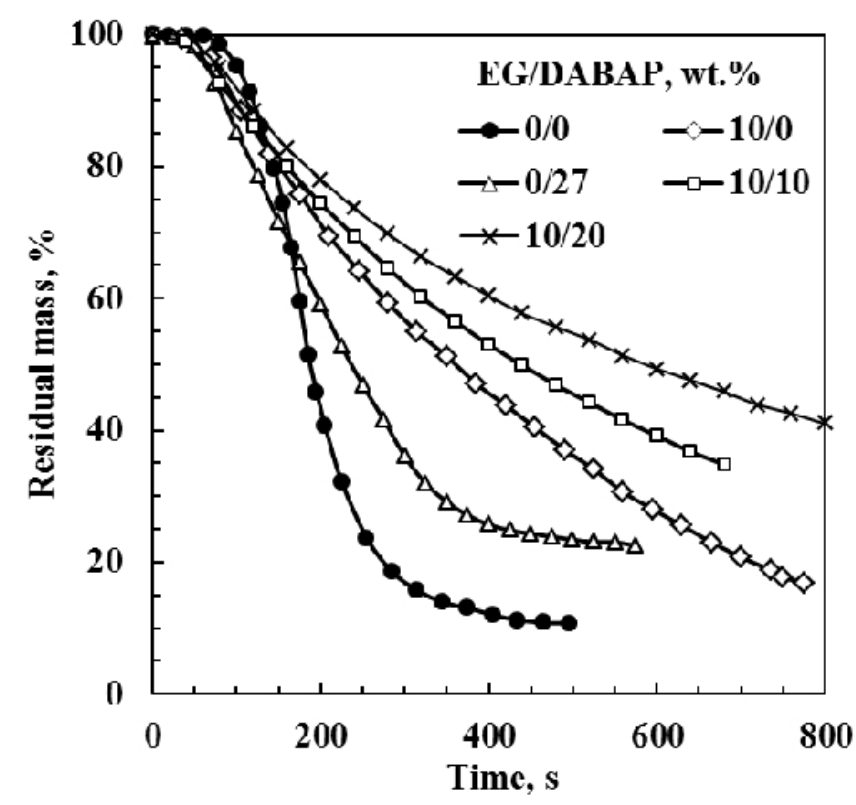

FIGURE 9 Cone calorimeter mass loss curves for the polyethylene compounds with expandable graphite and DABAP. The sample sheets were backed by aluminium foil and their dimensions were $100 \mathrm{~mm} \times 100 \mathrm{~mm} \times 3.2 \mathrm{~mm}$. They were mounted horizontally and exposed from above to an external heat flux of $35 \mathrm{~kW} \mathrm{~m}^{-2}$.

Table 2 lists the ignition and flame out times for the various samples. Addition of the flame retardants increased the propensity of the material to ignite. The time to ignition $\left(t_{\mathrm{ig}}\right)$ was $58 \pm 3 \mathrm{~s}$ for the neat polyethylene and $46 \pm 1 \mathrm{~s}$ for the compound containing $10 \mathrm{wt}$.\% EG but decreased to $33 \pm 5$ for the compound containing $27 \mathrm{wt} . \%$ DABAP. The lower ignition times are tentatively attributed to rapid 
decomposition of the intumescent flame retardants occurring at a lower temperature than for the neat polymer. This means that more flammable volatiles are release at an earlier stage in sufficient quantities to allow ignition to occur.

The time to flame out showed considerable variability. See Table 2 . It was $773 \pm 307$ for the neat polyethylene, reduced to $539 \pm 69$ for the $27 \mathrm{wt} . \%$ DABAP compound and was longer than both these times for all other compounds.

Figure 10 compares the smoke production rates (SPR) of the composites with that for the neat polyethylene. All the compounds containing expandable graphite showed very similar performance with a considerable reduction in smoke generation. Adding DABAP lowered the peak smoke production rate but the total amount of smoke released was higher. A potential explanation is as follows. The rate of smoke reduction is reduced owing to the barrier properties of the char layer that forms on the surface. However, ultimately more smoke is released because the aromatic additive itself has a greater tendency to produce smoke that the aliphatic polymer matrix.

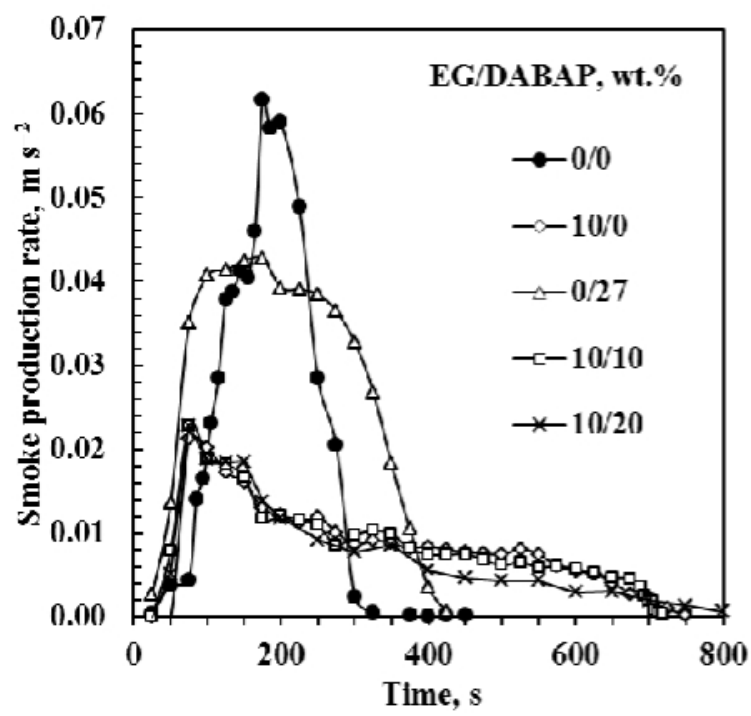

FIGURE 10 Cone calorimeter smoke production curves for the polyethylene compounds with expandable graphite and DABAP. The sample sheets were backed by aluminium foil and their dimensions were $100 \mathrm{~mm} \times 100 \mathrm{~mm} \times 3.2$ $\mathrm{mm}$. They were mounted horizontally and exposed from above to an external heat flux of $35 \mathrm{~kW} \mathrm{~m}^{-2}$.

Figure 11 and Figure 12 show the $\mathrm{CO}_{2}$ and $\mathrm{CO}$ release rate curves. The observed trends for $\mathrm{CO}_{2}$ mirror those observed for the HRR (Figure 7) almost perfectly. This is expected as the heat release rate correlates with the oxygen consumption and hence the rate of $\mathrm{CO}_{2}$ production. The curves for $\mathrm{CO}$ are more complex especially in the case of the $27 \mathrm{wt}$.\% DABAP compound. The cause for this behaviour is not currently understood but it could be related to the particular way DABAP decomposes under simulated fire scenarios. Although the peak rate of $\mathrm{CO}$ release was higher for the neat polyethylene, the 
total amount produced by the additive containing compounds appears to be higher. However this is not significant as the $\mathrm{CO}$ production rate was almost two orders of magnitude lower than that of $\mathrm{CO}_{2}$.

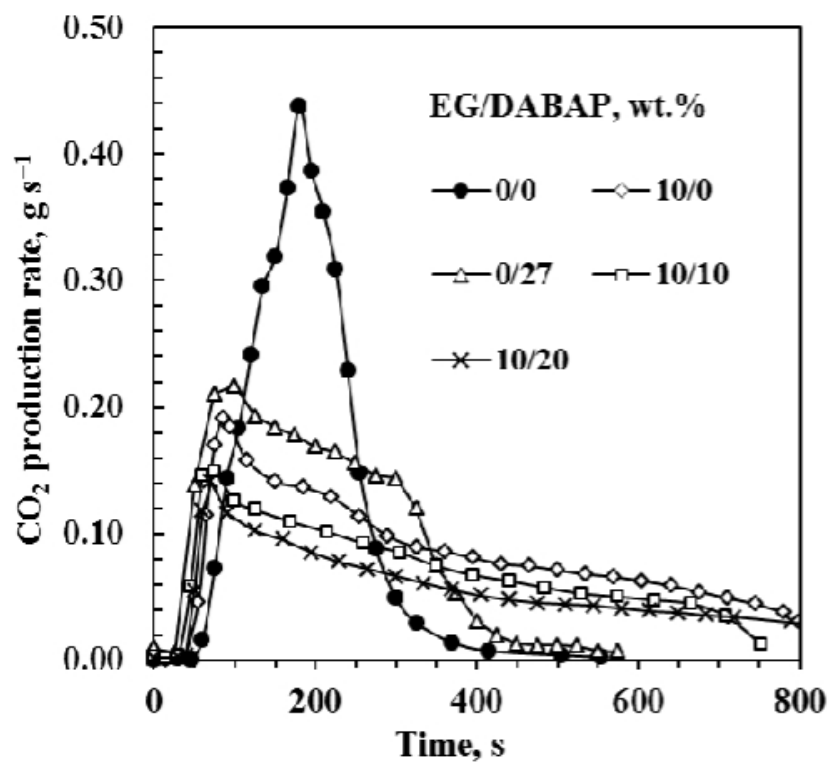

FIGURE 11 Cone calorimeter $\mathrm{CO}_{2}$ production curves for the polyethylene compounds with expandable graphite and DABAP. The sample sheets were backed by aluminium foil and their dimensions were $100 \mathrm{~mm} \times 100 \mathrm{~mm} \times 3.2 \mathrm{~mm}$. They were mounted horizontally and exposed from above to an external heat flux of $35 \mathrm{~kW} \mathrm{~m}^{-2}$.

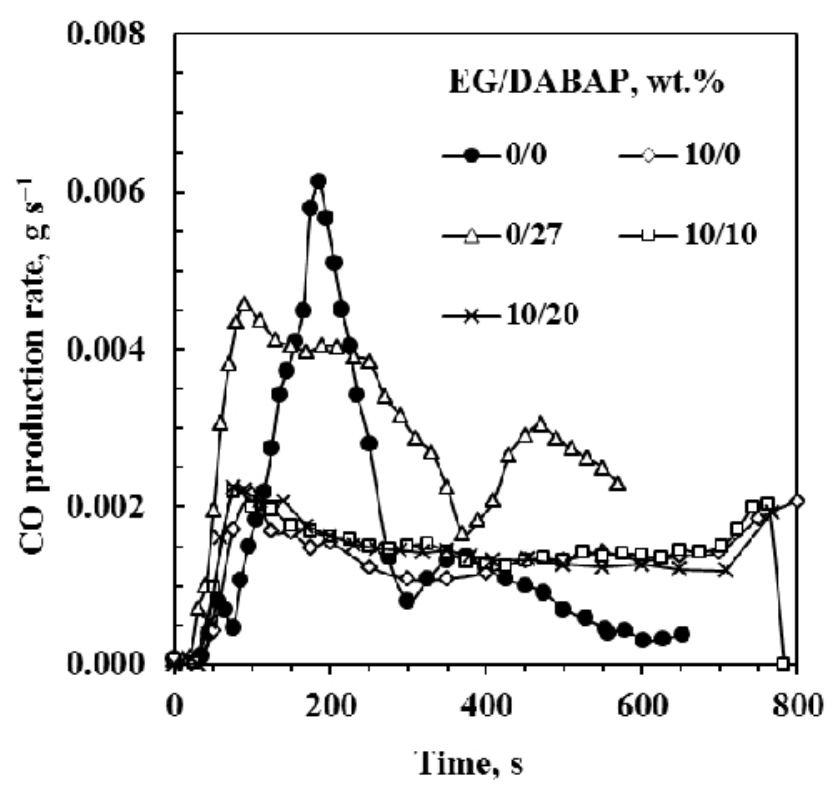

FIGURE 12 Cone calorimeter CO production curves for the polyethylene compounds with expandable graphite and DABAP. The sample sheets were backed by aluminium foil and their dimensions were $100 \mathrm{~mm} \times 100 \mathrm{~mm} \times 3.2 \mathrm{~mm}$. They were mounted horizontally and exposed from above to an external heat flux of $35 \mathrm{~kW} \mathrm{~m}^{-2}$. 
The fire growth rate (FIGRA) and the maximum average rate of heat emission (MAHRE) are indices that may be used to interpret cone calorimeter data. ${ }^{19,20}$ The MARHE parameter is defined as the peak value of the cumulative heat emission divided by time ${ }^{20}$. It provides a measure of the propensity for fire development under real scale conditions. ${ }^{20}$ The FIGRA is an estimator for the fire spread rate and size of the fire whereas the MARHE guesstimates the tendency of a fire to develop. ${ }^{20}$ The FIGRA is determined as

FIGRA $=p H R R /$ time to $p H R R$

Table 2 lists the FIGRA and MAHRE indices. A marked reduction of up to $50 \%$ relative to the neat polyethylene was observed for the MAHRE measured for the 10 wt.\% EG - 20 wt.\% DABAP combination. The FIGRA values, although somewhat reduced, did not differ markedly from those of the neat polyethylene.

The parameters that are pertinent to fire hazards are the fire load and flame spread. ${ }^{19}$ The Petrella plot is an attempt to gauge the magnitude of the fire hazard posed. ${ }^{19,21}$ It is a plot of the total heat evolved $t H R$ (as fire load) against $p H R R / t_{\text {ig }}$ (as a fire growth index). For a material to be effectively flame retarded both the fire load and the fire growth index should assume low values. Figure 13 shows a Petrella plot for the present formulations.

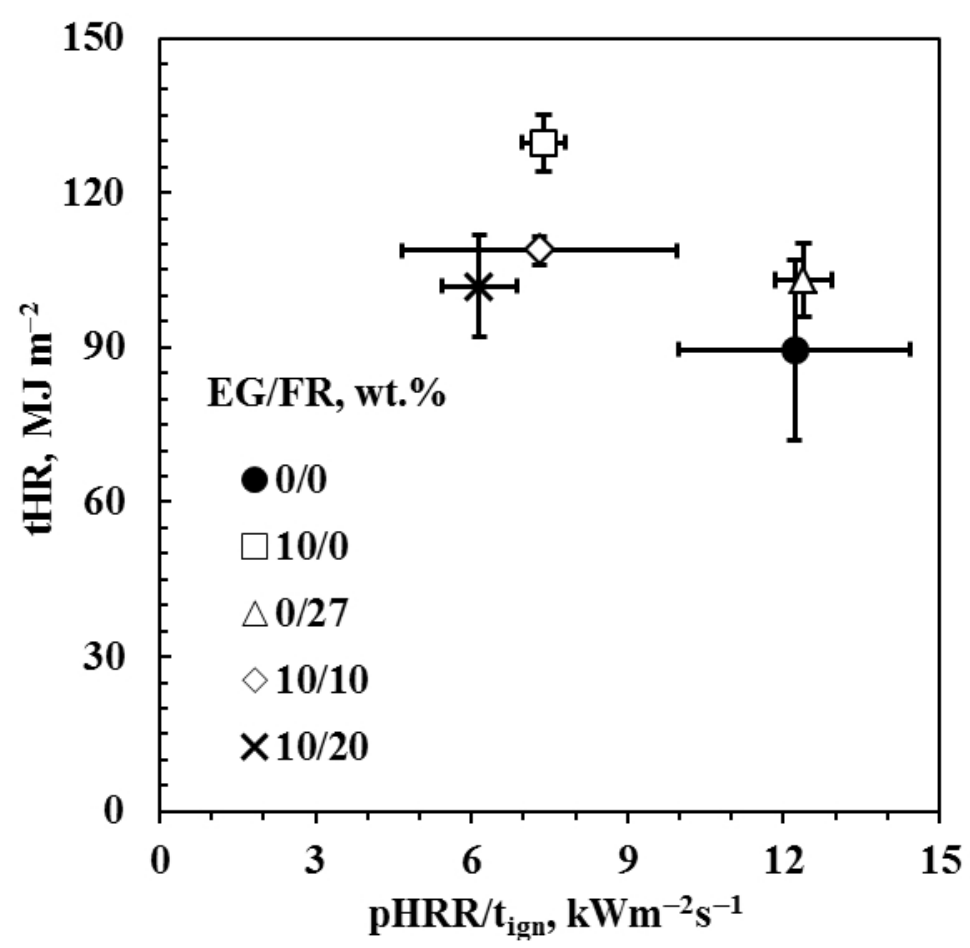

Figure 13 Petrella plot ${ }^{21}$ for the polyethylene compounds with expandable graphite and DABAP. The sample sheets were backed by aluminium foil and their dimensions were $100 \mathrm{~mm} \times 100 \mathrm{~mm} \times 3.2 \mathrm{~mm}$. They were mounted horizontally and exposed from above to an external heat flux of $35 \mathrm{~kW} \mathrm{~m}^{-2}$. 
Except for the $27 \mathrm{wt} . \%$ DABAP compound, all the other flame retarded compounds showed a decrease in the $p H R R / t_{\text {ig }}$ parameter but a slight increase in the heat load. The former performed slightly worse than the neat polyethylene according to both Petrella parameters. The reason for this is that the ignition time reduction was higher than the reduction in the peak heat release rate. The overall heat load was also higher than that of the neat polyethylene.

\section{CONCLUSIONS}

The phosphate salt of 3,5-diaminobenzoic acid was obtained by a facile precipitation reaction. This compound has a relatively high thermal stability. It commences to soften and melt at $257{ }^{\circ} \mathrm{C}$ and simultaneously decomposes with rapid mass loss up to ca. $17 \mathrm{wt} . \%$ observed just above this temperature. This is attributed to a decarboxylation reaction that releases $\mathrm{CO}_{2}$. The thermal decomposition proceeded stepwise at higher temperatures and resulted in a char yield at $900{ }^{\circ} \mathrm{C}$ of ca. 27 wt.\%.

The flame retardant performance of this compound on its own, and in combination with a high thermalstability expandable graphite, was evaluated by cone calorimetry. Polyethylene containing $5 \mathrm{wt} . \%$ carbon black was used as reference. Cone calorimeter results revealed that adding $10 \mathrm{wt} . \%$ expandable graphite lowered the peak heat release rate of carbon black-pigmented polyethylene from $710 \pm 109 \mathrm{~kW}$

$\mathrm{m}^{-2}$ to $342 \pm 15 \mathrm{~kW} \mathrm{~m}^{-2}$, while the compound containing $27 \mathrm{wt} . \%$ of the intumescent and $3 \mathrm{wt} . \%$ carbon black lowered it to $400 \pm 16 \mathrm{~kW} \mathrm{~m}^{-2}$. Combinations of these two additives decreased the peak heat release rate even further.

The intumescent additive reduced the flame out time from $773 \pm 307 \mathrm{~s}$ to $537 \pm 69 \mathrm{~s}$ while all other samples containing expandable graphite increased it. On the other hand, the addition of the expandable graphite had a much greater effect on reducing smoke emission.

All present additives caused a marginal decrease in the FIGRA fire index. The $10 \mathrm{wt} . \%$ expandable graphite 20 wt.\% intumescent combination caused a staggering reduction of $50 \%$ in the MAHRE value. The Petrella plot (Figure 13), an alternative measure of the flame retarding ability of a compound, indicated only marginal performance differences between the formulations tested.

\section{ACKNOWLEDGEMENTS}

This work is based upon research supported by the South African Research Chairs Initiative of the Department of Science and Technology (DST) and the National Research Foundation (NRF). Any opinion, findings and conclusions or recommendations expressed in this material are those of the authors and therefore the NRF ad DST do not accept any liability with regard thereto. 


\section{REFERENCES}

1. Weil, E. D.; Levchik, S. V., Journal of Fire Sciences 26, 52008.

2. Babrauskas, V.; Peacock, R. D., Fire Safety Journal 18, 2551992.

3. Dasari, A.; Yu, Z. Z.; Cai, G. P.; Mai, Y. W., Progress in Polymer Science 38, 13572013.

4. Qu, B.; Xie, R., Polymer International 52, 14152003.

5. Xie, R.; Qu, B., Journal of Applied Polymer Science 80, 11812001.

6. Xie, R.; Qu, B., Journal of Applied Polymer Science 80, 11902001.

7. Pang, X. Y.; Song, M.: 2012, p 779.

8. $\quad$ Sun, Z.; Ma, Y.; Xu, Y.; Chen, X.; Chen, M.; Yu, J.; Hu, S.; Zhang, Z., Polymer Engineering and Science2013.

9. Han, Z.; Li, Y.; Zhao, H., 2007, pp 828.

10. Camino, G.; Costa, L.; Martinasso, G., Polymer Degradation and Stability 23, 3591989.

11. Wang, J. Q.; Chow, W. K., Journal of Applied Polymer Science 97, 3662005.

12. Lewin, M., Journal of Fire Sciences 17, 31999.

13. Furdin, G., Fuel 77, 4791998.

14. Camino, G.; Duquesne, S.; Delobel, R.; Eling, B.; Lindsay, C.; Roels, T. In Fire and Polymers; American Chemical Society, 2001, Chap. 8.

15. Wissler, M., Journal of Power Sources 156, 1422006.

16. Chung, D. D. L., Journal of Materials Science 22, 41901987.

17. Chung, D. D. L., Journal of Materials Science 37, 14752002.

18. Coates, J. in Encyclopedia of Analytical Chemistry; Meyers, R., Ed.; John Wiley \& Sons Ltd, Chichester: 2000, p 10815.

19. Schartel, B.; Hull, T. R., Fire and Materials 31, 3272007.

20. Sacristán, M.; Hull, T. R.; Stec, A. A.; Ronda, J. C.; Galià, M.; Cádiz, V., Polymer Degradation and Stability 95, 12692010.

21. Petrella, R. V., Journal of Fire Sciences 12, 141994.

\section{Punblished as:}

Walter W. Focke, Herman Kruger, Washington Mhike, Albertus Taute, Albert Roberson and Osei Ofosu. Polyethylene flame retarded with expandable graphite and a novel intumescent additive. Journal of Applied Polymer Science Volume 131, Issue 13, 5 July 2014. http://onlinelibrary.wiley.com/doi/10.1002/app.40493/abstract DOI: 10.1002/app.40493

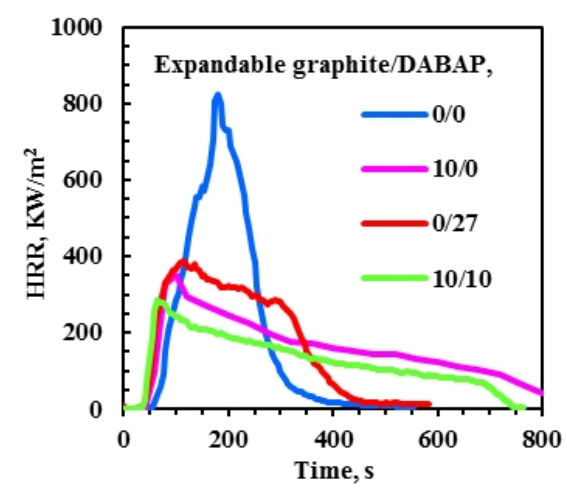

